\title{
Lead Isotopes and the chemical composition of silver items reveal developments in the Mediterranean metal trade during the Bronze and Iron Ages
}

\author{
TZILLA ESHEL ${ }^{1,2}$, AYELET GILBOA $^{3}$, NAAMA
}

YAHALOM-MACK ${ }^{4}$ AND YIGAL EREL ${ }^{5}$

${ }^{1}$ Ariel University

${ }^{2}$ University of Haifa

${ }^{3}$ Zinman Institution of Archaeology, University of Haifa

${ }^{4}$ Hebrew University

${ }^{5}$ Hebrew University of Jerusalem

Presenting Author: tzillaeshel@gmail.com

Lead Isotopes and the chemical composition of silver items reveal developments in the Mediterranean metal trade during the Bronze and Iron Ages.

Silver, before the invention of coins, was the dominant means of value and exchange in the southern Levant. Approximately 40 silver hoards, unearthed in various contexts, assert that silver served as currency in the Levant throughout the Bronze and Iron Ages. The hoards were studied for their chronology, context and content, and the silver was subjected to chemical and isotopic analysis. The results of this study reveal a persistent, wide diversity in silver sources. In several sub-periods within the Bronze and Iron Ages, clear changes in ore sources can be pointed out. Each such change has broad implications on the study of long-distance maritime trade in the Bronze and Iron Ages because silver-bearing lead ores do not occur in the Levant. Using an interdisciplinary approach, we combined geochemical methods and careful archaeological investigation in order to associate between changes in silver ore sources and transformations in regional trade systems, which are often imperceptible in ceramics. 